\title{
Deriving pasture growth patterns for Land Use Capability Classes in different regions of New Zealand
}

\author{
R. CICHOTA, I. VOGELER, F.Y. LI and J. BEAUTRAIS \\ AgResearch Grasslands, Private Bag 11008, Palmerston North 4442 \\ iris.vogeler@agresearch.co.nz
}

\begin{abstract}
Farm system models are increasingly being used to assess the implications of land use and practice changes on profitability and environmental impacts. Exploring implications beyond individual farms requires the linkage of such models to land resource information, which for pastoral systems includes forage supply. The New Zealand Land Resource Inventory (LRI) and associated Land Use Capability (LUC) database includes estimates of the potential stock carrying capacity across the country, which can be used to derive annual, but not seasonal, patterns of pasture growth. The Agricultural Production Systems Simulator (APSIM) was used, with generic soil profiles based on descriptions of LUC classes, to generate pasture growth curves (PGCs) in three regions of the country. The simulated pasture yields were similar to the estimates in the LRI spatial database, and varied with LUC Class within and across regions. The simulated PGCs also agreed well with measured data. The approach can be used to obtain spatially discrete estimates of seasonal pasture growth patterns across New Zealand, enabling investigation of land use and management changes at regional scales.
\end{abstract}

Key words: APSIM modelling, pasture growth curve (PGC), year to year variability, farm system analysis

\section{Introduction}

The Land Use Capability (LUC) classification system has been developed in New Zealand to assist sustainable land management (Lynn et al. 2009). The system has three hierarchical levels - LUC Class, LUC Subclass, and LUC Unit. The LUC Class provides an assessment of the land's capability for sustained primary production, taking into account its physical limitation and its versatility. The land is classified into eight classes, with LUC Class 1 being elite/versatile land with no limitations and LUC Class 8 land being unsuitable for primary production. LUC Subclasses are classified according to the main physical limitation or hazards for use. The LUC Subclasses can be subdivided further into a number of LUC Units, which group areas with similar landscape characteristics. Within these LUC Units land requires similar management and conservation treatment, and is suitable for the same kind of crops, pasture or forestry species, with similar potential yield.

Farm system and nutrient budget models are being used increasingly to assess the long-term implications of land use and farming practices on profitability and ground and surface water quality. To explore implications beyond individual farm boundaries requires the linking of such models to land resource information, including information on potential uses and productive capacity (Vogeler et al. 2014). For a pastoral system this includes pasture yields and seasonal pasture growth patterns. The extended legend of the LUC worksheets, part of the New Zealand Land Resource Inventory (NZLRI), provides estimates of the livestock carrying capacity (CC) of a ryegrass/white clover mixed pasture for each LUC Unit throughout New Zealand (Newsome et al. 2000). From this CC the annual dry matter intake (DMI) from each LUC Unit can be estimated. This DMI, when combined with the efficiency with which the grazing animals consume the pasture (pasture utilisation) can be used to estimate the annual DM Yield (DMY). For farm system analysis and management planning, in addition to annual pasture yield, the seasonal pattern of pasture growth is essential information. For many parts of New Zealand, however, there are limited data on this. The objective of this study was to develop and test a procedure to derive general pasture growth curves (PGC) for different LUC Classes in three regions of New Zealand and under three different climatic conditions within each region. This was done using APSIM, a deterministic model, which was used to simulate pasture growth from a range of soil profiles, representing three different LUC classes, with long-term (30 years) historic weather data.

\section{Materials and Methods \\ Expert-estimated herbage production of pastures in different LUC Classes}

As part of the NZLRI, the livestock carrying capacity for each LUC Unit has been estimated by a group of experts for each region of New Zealand. This information has been compiled, and provided in the "Land resource information system spatial data" (Newsome et al. 2000). This spatial database comprises three different 
estimates of CC for each LUC: potential, and those achieved by a top and an average farmer. Information on the extent of each LUC Unit and livestock carrying capacity were extracted from this database, and used to calculate the weighted average livestock carrying capacity $(C)$ for each LUC Class in a region, that is,

$C=\sum(C C i \times A i)$ (stock units per ha)

where $C C i$ and $A i$ are the livestock carrying capacity and the land area percentage of each LUC Unit for a LUC Class in a region. The average livestock carrying capacity was converted to annual DMI of the livestock by multiplication with the DMI of a standard stock unit (550 kg DM per annum; Coop 1965).

$$
D M I=550 \times C(\mathrm{~kg} \mathrm{DM} / \text { per ha })
$$

\section{The model and the simulation setup}

The Agricultural Production System Simulator (APSIM; Holzworth et al. 2014) was used to simulate the seasonal pattern of pasture growth. The performance of the pasture model, AgPasture, has been validated against long-term pasture measurement on various soil types and across different climatic zones in New Zealand (Li et al. 2011). Other major modules used in the simulation setup included SWIM3 for soil water and solute movement (Huth et al. 2012), SoilN for soil nitrogen and carbon dynamics, as well as modules for fertiliser applications and pasture management. Runoff in APSIM is based on the curve number $(\mathrm{CN})$ approach
(Ponce \& Hawkins 1996), which captures the effects of slope and infiltration capacity by a characteristic $\mathrm{CN}$. The $\mathrm{CN}$ typically ranges from 50 to 100 , with a higher number for higher runoff risk.

To capture variation in climatic conditions across each of the three regions, pasture growth was simulated for separate sites in each of the three Regions: Balclutha, Wyndham and Mokoreta in Southland; Alford Forest, Darfield and Lincoln in Canterbury; and Pukekohe, Ruakura and Whatawhata in Waikato. For each site, virtual climate station data (Tait et al. 2006) were used, and the simulations were run on the six soil profiles (Table 1) over 30 years (1980-2009). The effect of slope and aspect on radiation was calculated following the approach of Revfeim (1982). The pasture was cut every 3 weeks to a residual of $1250 \mathrm{~kg} \mathrm{DM} /$ ha, mimicking rotational grazing of a sheep and beef system.

\section{Setup of soil profiles for different LUC Classes}

To obtain estimates for the annual dry matter yield and seasonal pattern for a selection of different LUC Classes, two sets of soil parameters were developed to represent approximately the LUC Subclasses soil ("s") and wetness ("w") (Lynn et al. 2009). Based on the general description of these LUC Subclasses, six generic soil profiles were defined using information available on the New Zealand National Soils Database (Wilde 2003). Main differences in the soils relevant for our modelling included soil rooting depth (depth

Table 1 Landscape and soil characteristics used in APSIM to simulate pasture growth on three LUC Subclasses (2s and w, 4s and $w, 6 s$ and $w$ ) with PAW = Plant Available Water, and IP = Impeding layer with a saturated hydraulic conductivity of $0.1 \mathrm{~mm} /$ day.

\begin{tabular}{|c|c|c|c|}
\hline \multirow{2}{*}{$\begin{array}{l}\text { LUC } \\
\text { Class }\end{array}$} & \multirow[t]{2}{*}{ Basic physical characteristics } & \multicolumn{2}{|c|}{ Soil parameters in model } \\
\hline & & Light ('s' subclass) & Heavy ('w' subclass) \\
\hline \multirow[t]{5}{*}{2} & Moderate soil depth $(45-90 \mathrm{~cm})$ & Soil root depth $70 \mathrm{~cm}$ & Soil root depth $70 \mathrm{~cm}$ \\
\hline & Low (1-2 days of water logging) & & IP at $70 \mathrm{~cm}$ \\
\hline & or no drainage limitation & PAW: $89 \mathrm{~mm}$ & PAW: $96 \mathrm{~mm}$ \\
\hline & Flat or undulating $\left(0-7^{\circ}\right)$ & Texture: Sandy loam & Texture: Silty clay loam \\
\hline & Mainly alluvium and recent loess soils & Flat with curve number 60 & Flat with curve number 65 \\
\hline \multirow[t]{5}{*}{4} & Shallow soil depth $(20-45 \mathrm{~cm})$ & Soil root depth $45 \mathrm{~cm}$ & Soil root depth $45 \mathrm{~cm}$ \\
\hline & Low to moderate drainage limitation & & IP at $45 \mathrm{~cm}$ \\
\hline & (2-4 days of water logging) & PAW: $50 \mathrm{~mm}$ & PAW: $53 \mathrm{~mm}$ \\
\hline & Flat to strongly rolling $\left(16-20^{\circ}\right)$ & Texture: Sandy loam & Texture: Silty clay loam \\
\hline & Clayey or sandy soils, very stony & Rolling with curve number 73 & Rolling with curve number 78 \\
\hline \multirow[t]{5}{*}{6} & Very shallow soil depth $(<20 \mathrm{~cm})$ & Soil root depth $25 \mathrm{~cm}$ & Soil root depth $25 \mathrm{~cm}$ \\
\hline & Moderate to high drainage limitation & & IP at $25 \mathrm{~cm}$ \\
\hline & (8-15 days of water logging) & PAW: $24 \mathrm{~mm}$ & PAW: $26 \mathrm{~mm}$ \\
\hline & Steep and very steep $\left(>26^{\circ}\right)$ & Texture: Sandy loam & Texture: Silty clay loam \\
\hline & Clayey or sandy soils, very stony & Steep with curve number 85 & Steep with curve number 90 \\
\hline
\end{tabular}


to gravel or impeding layer), plant available water content, water drainage class (for Subclasses " $w$ " an impeding layer below the rootzone was used), runoff risk, and slope of the land (Table 1). To account for differences in soil fertility depending on slope class, different Olsen P (phosphorus) values were assumed, based on experimental data from New Zealand (Saggar et al. 1990; Rowarth et al. 1992; Mackay \& Lambert 2011), with 20, 15 and $11 \mu \mathrm{g} \mathrm{P} / \mathrm{ml}$ for LUC Classes 2, 4 and 6. In APSIM a Michaelis-Menten function was used to capture the effect of Olsen P on pasture growth, based on results from Mouat \& Nes (1983) and Mackay et al. (2010).

\section{Simulation of pasture growth}

The APSIM model, with the soil profiles described above, was used to derive seasonal pasture growth rates on LUC $2 \mathrm{~s}$ and $\mathrm{w}, 4 \mathrm{~s}$ and $\mathrm{w}$, and $6 \mathrm{~s}$ and $\mathrm{w}$ under a range of different climatic conditions within each of three regions of the country. We assumed the pasture to be a mixture of perennial ryegrass, white clover, and different proportions of low fertility tolerant species. Based on experimental data from around New Zealand (Suckling 1960; Ledgard et al. 1982; Moir et al. 2013) the yield and percentage of low fertility species depending on slope class was set in APSIM: a relative yield of $75 \%$ was used for low fertility species, and these comprised 20,60 , and $80 \%$ of the pastures on LUC Classes 2, 4 and 6.

\section{Analysis of simulated pasture growth against long- term observations}

The simulated daily pasture growth rates ( $\mathrm{kg} \mathrm{DM} / \mathrm{ha} /$ day) for each simulation scenario at each site, based on characteristic soil profiles derived from LUC land descriptions, were summarised into monthly mean daily pasture growth rates, and these PGCs were then compared with available pasture growth data from Woodlands (Smith 2012) in Southland, Winchmore (White et al. 2008) in Canterbury, and Whatawhata (Dodd et al. 2008) and Ruakura (Li et al. 2011) in Waikato. Mean annual DMY over 30 years were also aggregated, and the DMY across LUC Classes in different regions were compared with those derived from the potential carrying capacity, based on expert estimates.

\section{Results and Discussion \\ Simulated DMY versus expert-estimated annual DMI of pastures in different LUC Classes}

Simulated annual DMY across the sites generally align well with the estimates of potential DMI derived from the livestock carrying given in the NZLRI (Figure 1). While for the high LUC Classes in Canterbury and Southland potential DMI is lower than the DMY simulated by APSIM, the values are within the range of estimated potential DMI (within one standard deviation). As expected, simulated annual DMY declined with increasing LUC Classes, due to limitation of soil physical constraints in the soil profiles (Table 1). Calculated pasture utilisation (PU) rates for potential, top and average farmer (based on DMI/DMY) are lower at higher LUC Classes (Table 2). While the utilisation rates for potential livestock carrying capacity are slightly higher than expected, with an achievable DMY of $95 \%$ and a PU of 90 (Sinclair \& Cornforth 1984), the PU for top and average farmers are in the range of reported data for the North and South Island of New Zealand (Abrahamson \& Darkey 1988).

This general agreement between DMY and potential

Table 2 APSIM simulated annual dry matter yield (DMY, kg/ha) for three LUC Classes, and expert-estimated dry matter intake (DMI) based on the livestock carrying capacity from the New Zealand Land Resources Inventory, potentially achievable and for a top and average farmer. Values in brackets give the utilisation rate (\%) based on the simulated DMY.

\begin{tabular}{|c|c|c|c|c|c|}
\hline & \multirow{2}{*}{$\begin{array}{l}\text { LUC } \\
\text { Class }\end{array}$} & \multirow{2}{*}{$\begin{array}{l}\text { Annual } \\
\text { DMY }\end{array}$} & \multicolumn{3}{|c|}{ Annual expert estimated DMI } \\
\hline & & & Potential & Top Farmer & Avg Farmer \\
\hline \multirow[t]{3}{*}{ Waikato } & 2 & 13941 & $13804(99)$ & $12032(86)$ & $8983(64)$ \\
\hline & 4 & 11270 & $10913(97)$ & $9051(80)$ & $6917(61)$ \\
\hline & 6 & 8493 & $9190(108)$ & $7771(92)$ & $6372(75)$ \\
\hline \multirow[t]{3}{*}{ Canterbury } & 2 & 9241 & $9641(104)$ & $8448(91)$ & $6792(74)$ \\
\hline & 4 & 7502 & $6166(82)$ & $5029(67)$ & $3436(46)$ \\
\hline & 6 & 5467 & $3818(70)$ & $2801(51)$ & $1410(26)$ \\
\hline \multirow[t]{3}{*}{ Southland } & 2 & 11391 & $11760(103)$ & $10338(91)$ & $8716(77)$ \\
\hline & 4 & 9540 & $8685(91)$ & $6843(72)$ & $5171(54)$ \\
\hline & 6 & 7425 & $5643(76)$ & $3488(47)$ & $2630(35)$ \\
\hline
\end{tabular}



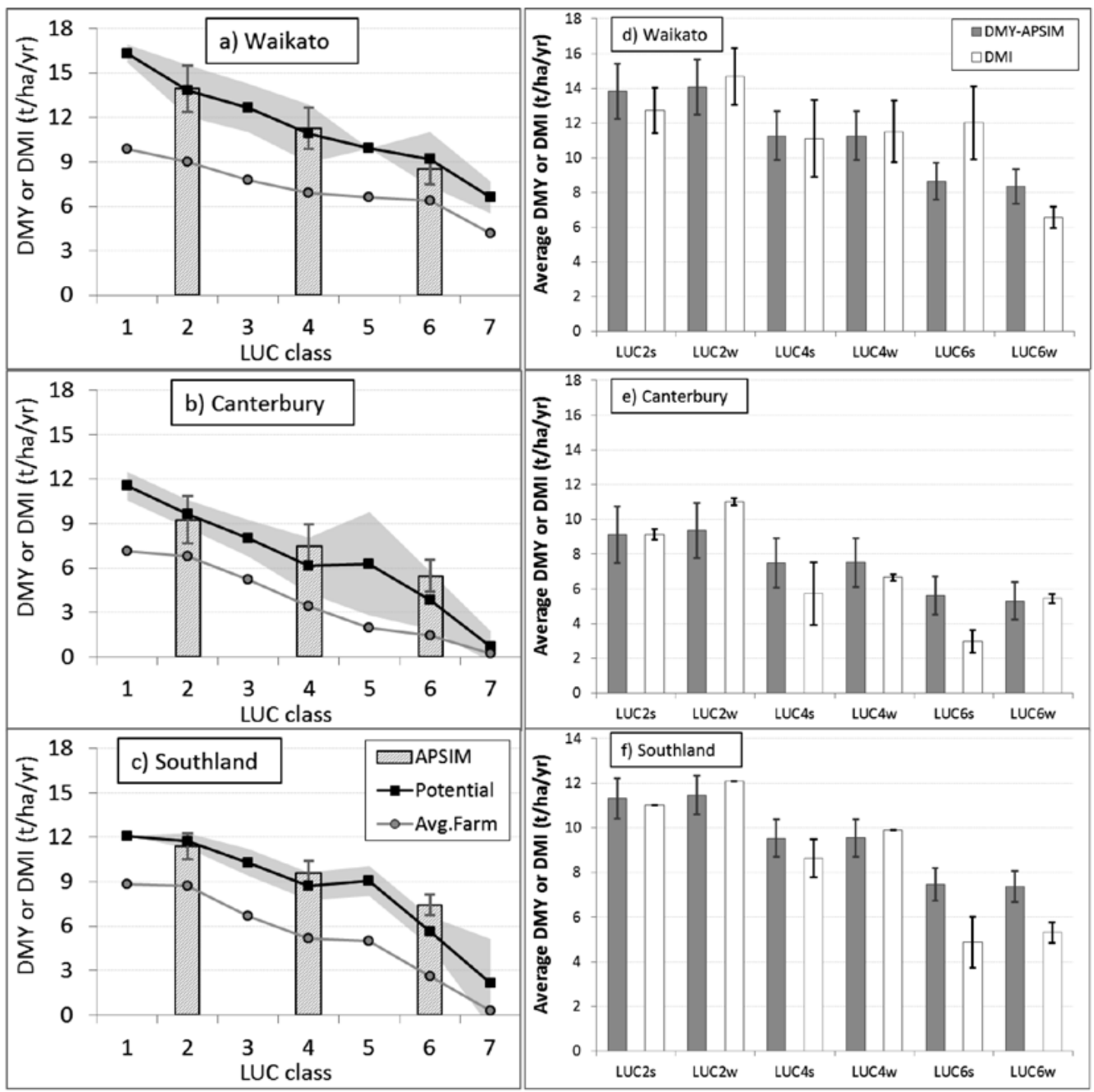

Figure 1 a-c)

Simulated annual Dry Matter Yields (DMYs) using the APSIM model and land area-weighted average annual animal dry matter intake (DMI) calculated from expert estimates of livestock carrying capacity for different LUC Classes in three regions. Shown are potential DMI and that of an "average farmer", as provided in the New Zealand Land Resources Inventory. The shaded area shows the variability of the potential DMI (one standard deviation) for each LUC class and region. The simulated DMYs are the averages of two soils (subclasses " $s$ " and " $w$ ") and of three sites in a region, with vertical bars showing the inter-annual variability (one standard deviation averaged at three sites). d-f) Comparison of the APSIM simulated DMY and DMI calculated from expert-estimates of potential carrying capacity on the LUC Subclass "s" and " $w$ " in three LUC Classes in three regions.

DMI (derived from the carrying capacity) suggests that our approach of defining generic soil profiles for the different LUC Subclasses and using them across different regions can be used with some confidence to estimate DMY across New Zealand. One reason for the slightly higher simulated DMY at high LUC Classes compared with potential intake, might be the inclusion of "lower fertility vegetation" (i.e. tussock), which was not considered in our simulation. Our approach also provides information on the year-to-year variability in DMY (Figure 1) and pasture growth patterns (see below). Year to year variability of DMY is highest in Canterbury with coefficient of variations $(\mathrm{CV})$ of 17.3, 18.9 and $19.8 \%$ for LUC 2, 4 and 6; followed by Waikato with CVs of $11.4,12.5$ and $12 \%$; and lowest in Southland with CVs of $7.8,8.8$ and $9.7 \%$. 


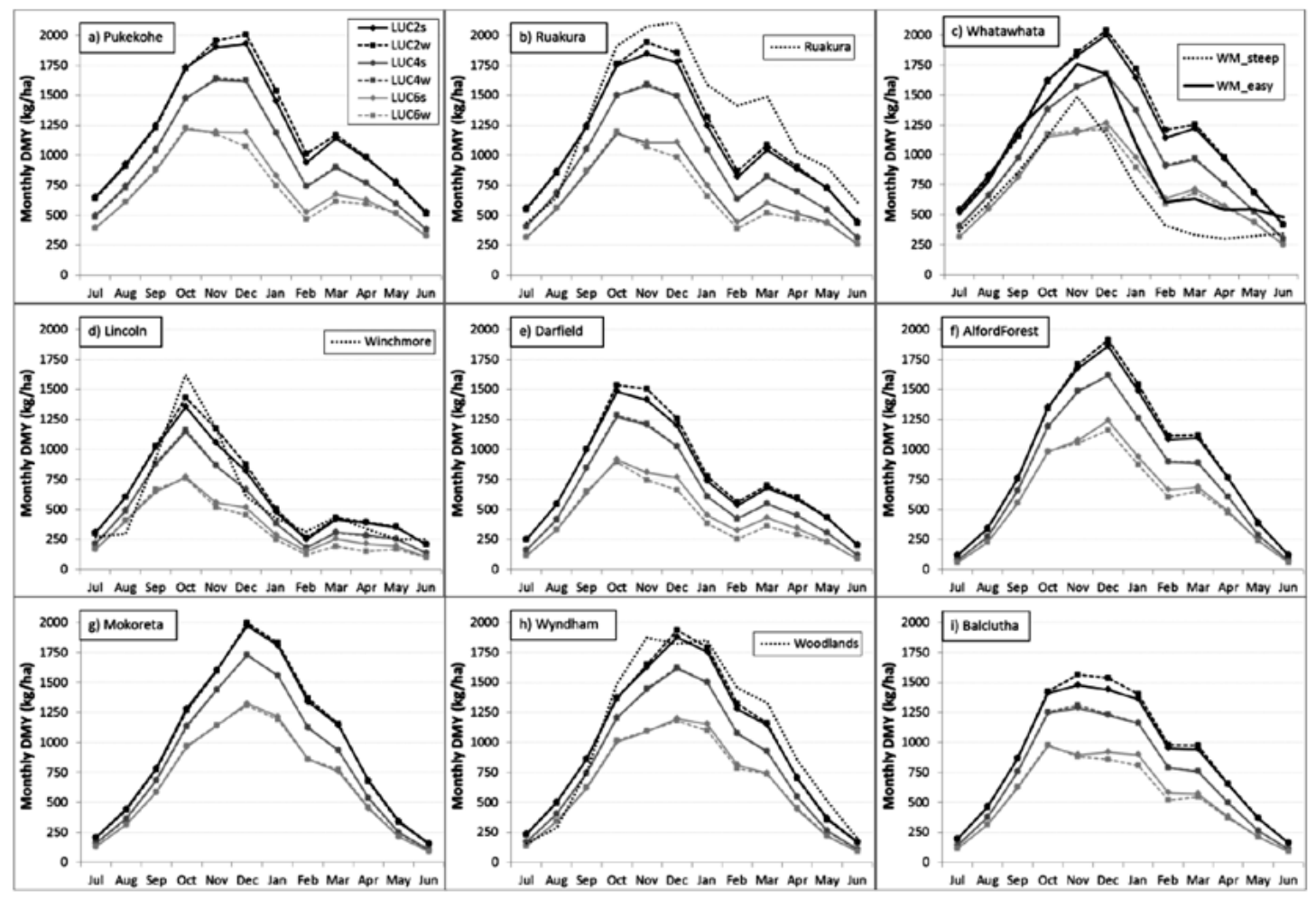

Figure 2 Simulated pasture growth curves at nine sites in three regions (Waikato: a, b, c; Canterbury: d, e, f; Southland: g, h, i). The pastures are on three pairs of soil types representing a well-drained (s) and a poorly-drained (w) soil for each of three LUC Classes in each region. The curves are the monthly mean pasture growth rate (PGR) over a 30 year period (1980-2009). Also shown are observed PGRs at Ruakura on LUC2, and Whatawhata on easy (LUC ca. 3) and steep (LUC ca. 6 to7) terrain in Waikato, at Winchmore (LUC ca. 3) in Canterbury, and at Woodlands (LUC Class 2).

\section{Difference between soil drainage properties}

Simulated annual DMY and DMI based on expert estimated carrying capacity generally show a similar trend with higher production on heavier soils (Subclass "w") compared with light soils (Subclass "s') of the same LUC Class in all three regions (Figures $1 \mathrm{~d}-\mathrm{g}$ ). This is mainly due to their slightly higher growth in summer. The large discrepancy between the simulated DMYs and expert-estimated DMI on high LUC Subclasses in Southland might, as discussed before, be due to inclusion of low fertility vegetation in the later. In general, differences between the simulated DMIs for the two soil types within the same LUC Class are small. This suggests that distinguishing light and heavy soil types is not as important as climatic variations for estimating the representative PGC of a LUC Class land in a region, though livestock carrying capacity might be different due to the low pasture utilisation on poorly than well drained soils.

\section{Pasture growth curves for different LUC Classes}

Simulated PGCs for the six different soils at nine sites of the three regions are shown in Figure 2, along with long-term monthly mean observed PGCs. The PGCs observed at Woodlands in Southland (2h) matched well with the average PGCs simulated for the same LUC Class (Class 2), and for Winchmore (LUC Class 3 ) in Canterbury the PGC observed was between the simulated mean PGCs for LUC Classes 2 and 4 (2d). For Whatawhata in Waikato the PGC of easy terrain matched that of LUC2, and the PGC of steep terrain was similar to that on LUC6. For Ruakura the PGC also generally followed that for LUC 2, but simulations showed lower pasture growth in summer. This discrepancy is likely due to the presence of paspalum (Paspalum dilatatum) in pastures in Waikato, which shows higher summer growth compared with ryegrass. In the simulation only a ryegrass/white clover pasture was considered. In general these results indicate a good approximation of the simulated PGCs for the specific LUC Classes in these three different regions. Further testing of our approach, especially for high LUC Class land is needed to increase our confidence in the use of these curves for investigation of land use and management changes at regional scales. 


\section{Conclusions}

Variations in the simulated annual dry matter yield (average over 30 years) within and across regions agreed well with that of expert estimates, based on the area averaged potential carrying capacity. Utilisation rates of top and average farmers within the different regions were in agreement with literature values. Differences between light and heavy soils within the same LUC Class were small; climate variations within a region were more important. Simulated pasture growth curves (PGCs) also agreed well with measured values, where available.

The PGCs for different LUC Classes in a region provide important information for supporting farm system modelling, as well as for regional land use and management planning. They provide not only information on average PGCs but also on year to year variability. The approach of linking LRI data with biophysical modelling can be used to obtain spatially discrete estimates of pasture production and seasonal patterns across New Zealand, enabling investigation of land use and management changes at regional scales. The approach has the potential to be used at the LUC Units level to produce more detailed information to support farm management.

\section{ACKNOWLEDGEMENTS}

Thanks to Alec Mackay, Grant Douglas and Mark Lieffering for valuable comments. This work was conducted under the Rural Futures programme which was initiated with FRST funding and has since been transferred to AgResearch's own Core Funding.

\section{REFERENCES}

Abrahamson, M.; Darkey, C., 1988. Phosphorus requirements and use for pastoral systems in New Zealand. Tussock Grasslands \& Mountain Lands Institute, p. 175.

Coop, I.E. 1965. A review of the ewe-equivalent system. New Zealand Agricultural Science 1: 13-18.

Dodd, M.B.: Wedderburn, M.E.; Parminter, T.G.; Thorrold, B.S.; Quinn, J.M. 2008. Transformation toward agricultural sustainability in New Zealand hill country pastoral landscapes. Agricultural Systems 98: 95-107.

Holzworth, D.P.; Huth, N.I.; deVoil, P.G.; Zurcher, E.J.; Herrmann, N.I.; McLean, G.; Chenu, K.; van Oosterom, E.J.; Snow, V.; Murphy, C.; Moore, A.D.; Brown, H.; Whish, J.P.M.; Verrall, S.; Fainges, J.; Bell, L.W.; Peake, A.S.; Poulton, P.L.; Hochman, Z.; Thorburn, P.J.; Gaydon, D.S.; Dalgliesh, N.P.; Rodriguez, D.; Cox, H.; Chapman, S.; Doherty, A.; Teixeira, E.; Sharp, J.; Cichota, R.; Vogeler, I.; Li, F.Y.; Wang, E.; Hammer, G.L.; Robertson, M.J.; Dimes, J.P.; Whitbread, A.M.; Hunt, J.; van Rees,
H.; McClelland, T.; Carberry, P.S.; Hargreaves, J.N.G.; MacLeod, N.; McDonald, C.; Harsdorf, J.; Wedgwood, S.; Keating, B.A. 2014. APSIM Evolution towards a new generation of agricultural systems simulation. Environmental Modelling and Software. DOI: 10.1016/j.envsoft.2014.07.009.

Huth, N.I.; Bristow, K.L.; Verburg, K. 2012. SWIM3: Model use, calibration and validation. Transactions of the ASABE, pp. 1303-1313.

Ledgard, S.F.; Sheath, G.W.; Gillingham, A.G. 1982. Influence of some soil and pasture components on the growth of hill country pastures. 1. Winter and spring production. New Zealand Journal of Experimental Agriculture 10: 239-244.

Li, F.Y.; Snow, V.O.; Holzworth, D.P. 2011. Modelling seasonal and geographical pattern of pasture production in New Zealand - validating a pasture model in APSIM. New Zealand Journal of Agricultural Research 54: 331-352.

Lynn, I.H.; Manderson, A.K.; Page, M.J.; Harmsworth, G.R.; Eyles, G.O.; Douglas, G.B.; Mackay, A.D.; Newsome, P.J.F. 2009. Land Use Capability Survey Handbook - a New Zealand handbook for the classification of land. AgResearch, Hamilton; Landcare Research, Lincoln; GNS Science, Lower Hutt.

Mackay, A.D.; Gillingham, A.G.; Smith, C.; Budding, P.; Phillips, P.; Clarke-Hill, W.; Johnstone, P. 2010. Evaluation of the effects of grass species, irrigation, nitrogen fertiliser application and soil compaction on the response of modern dairy pastures to phosphorus fertiliser. Proceedings of the New Zealand Grassland Association 72: 153-158.

Mackay, A.D.; Lambert, M.G., 2011. Long-term changes in soil fertility and pasture production under no, low and high phosphorous fertiliser inputs. Proceedings of the New Zealand Grassland Association 73: 37-42.

Moir, J.L.; Edwards, G.R.; Berry, L.N. 2013. Nitrogen uptake and leaching loss of thirteen temperate grass species under high $\mathrm{N}$ loading. Grass and Forage Science 68: 313-325.

Mouat, M.C.H.; Nes, P. 1983. Effect of the interaction of nitrogen and phosphorus on the growth of ryegrass. New Zealand Journal of Agricultural Research 26: 333-336.

Newsome, P.F.J.; Wilde, R.H.; Willoughby, E.J. 2000. Land resource information system spatial data layers. In: Ltd, L.R.N.Z. (Ed.), p. 74.

Ponce, V.M.; Hawkins, R.H.; 1996. Runoff curve number: Has it reached maturity? Journal of Hydrologic Engineering 1: 11-18.

Revfeim, K.J.A. 1982. Estimating global solar radiation on sloping surfaces. New Zealand Journal of Agricultural Research 25: 281-283. 
Rowarth, J.S.; Gillingham, A.G.; Tillman, R.W.; Syers, J.K. 1992. Effect of phosphate fertiliser addition and land slope on soil phosphate fractions. New Zealand Journal of Agricultural Research 35: 321-327.

Saggar, S.; Mackay, A.D.; Hedley, M.J.; Lambert, M.G.; Clark, D.A. 1990. A nutrient-transfer model to explain the fate of phosphorus and sulphur in a grazed hill-country pasture. Agriculture, Ecosystems and Environment 30: 295-315.

Sinclair, A.G.; Cornforth, I.S. 1984. A modification of the 'Superchoice' phosphate maintance model New Zealand Journal of Experimental Agriculture 12: 141-144.

Smith, L.C. 2012. Long-term pasture growth patterns for Southland, New Zealand. Proceedings of the New Zealand Grassland Association 74: 147-151.

Suckling, F.E.T. 1960. Productivity of pasture species on Hill Country. New Zealand Journal of Agricultural Research 3: 579-591.
Tait, A.; Henderson, R.; Turner, R.; Zheng, X. 2006. Thin plate smoothing spline interpolation of daily rainfall for New Zealand using a climatological rainfall surface. International Journal of Climatology 26: 2097-2115.

Vogeler, I.; Vibart, R.; Mackay, A.; Dennis, S.; Burggraaf, V.; Beautrais, J. 2014. Modelling pastoral farm systems - Scaling from farm to region. Science of the Total Environment 482-483: 305-317.

White, T.A.; Johnson, I.R.; Snow, V.O. 2008. Comparison of outputs of a biophysical simulation model for pasture growth and composition with measured data under dryland and irrigated conditions in New Zealand. Grass and Forage Science 63: 339349.

Wilde, R.H., 2003. Manual for National Soils Database. Landcare Research, Palmerston North, New Zealand. 